\title{
A Study on the Relationship among Management Staff's Job Experience, Ability Accumulation and Promotion Possibility
}

\author{
Yun-Mei Li \\ Center for Industrial Policy and Management Research, \\ Wuhan University of Science and Technology, No.947, \\ Heping Avenue, Qingshan District, Wuhan, China \\ Emaillymwust@163.com
}

\begin{abstract}
From the perspective of employees, the relationship model of promotion possibility, job experience and ability accumulation was established and verified bystructural equation model (SEM). Through empirical analysis, it is found that the evaluation of job experience can positively predict employee's promotion possibility and employee's ability accumulation;as the intermediary variable between the evaluation of job experience and employee's promotion possibility, employee's ability accumulation can positively predict employee's promotion possibility. Therefore, the degree of employee' sability accumulation could be used as a measure to quantify the job experience variables. The promotion possibility of staff can be identified as the objective basis of the fair and impartial selection of talents for enterprises.
\end{abstract}

Keywords- Job experience, Promotion possibility, Ability accumulation.

\section{INTRODUCTION}

Promotion is one of the organization's incentive means. It can not only meet the basic needs, such as salary increasing, getting the reward; but can also satisfy the high demands, such as self-actualization needs. However, from the perspective of employees, the existing promotion approaches couldn't been able to play a real good role of motivation, so employers should reform their policies of promotion and enhance the awareness of the cultivation of employee's self-promotion ability.

At home and abroad, the research on the promotion is abundant. Domestic scholars mainly focus on studying promotion's factors about local officials and leaders. The influencing factors of the promotion about local officials and leaders in China are "achievements theory" and "relationship theory"[1]. Foreign scholars mostly stand on the organizational level, through empirical analysis, study the relationship among promotion, organizational commitment, employee pay, job performance and other issues. Existing literature which study promotion from the perspective of employees is rare. Therefore, by reading a large number of Chinese and foreign literatures, combining with the enterprise promotion practice, the author proposed the concept of promotion possibility that employees' promotion depends on the degree of their promotion possibility. So what factors can affect the employees' promotion possibility? Through reading many literatures, the author found that job experience and ability

\author{
Luo-Na Zhang* \\ Center for Industrial Policy and Management Research, \\ Wuhan University of Science and Technology, No.947, \\ Heping Avenue, Qingshan District, Wuhan, China \\ Email:1169378018@qq.com
}

accumulation can affect the employees' promotion possibility. Therefore, by using the structural equation model, this paper studies the relationship among promotion possibility, ability accumulation and job experience, and obtains the standard of the employee' $\mathrm{s}$ promotion possibility, which is helpful for the enterprise to select talented person.

\section{THEORETICAL AND HYPOTHESIS}

Dynamic capability theory was first proposed by Teeceetal. They pointed out that: in order to respond to changes in the market, the dynamic capability theory is the process of the enterprise configuration, reconstruction of the internal and external capabilities [2]. Based on the theory of dynamic capabilities, Richardson et al. studied the enterprise capability accumulation, by improving enterprise's skills, knowledge and experience, making enterprise accumulate ability constantly, it can obtain comparative advantage in the fierce competition environment [3]. Based on the enterprise competence accumulation, Dragoni, Lisa claimed that the influencing factors of employees' ability accumulation is abundant job experience, the staff's rich job experience with the strategic thinking ability are positively related, so working experience is helpful for staff's capacity accumulation[4].

Based on the above theory, the following assumption is put forward:

H1: Evaluation of job experience has a positive impact on the employees' ability accumulation.

Huang Simei, Lian Zhaolong believed that every employee wants to defeat the competitors to get a promotion in the enterprise, but the emotions and conditions of promotion are not the same, so every time the promotions are full of changes because of the difference of people, time, and emotions in the situation, the effect factors of promotion possibility are including personal characteristics, work ability, work attitude, communication ability, human capital[5].When discussing the promotion of cadres, Yin Weiguo stressed the importance of the work experience of the cadres [6].Zhao Wenhua, Zhang Xinpei through quantifying personnel experience to study the work experience of those who have worked for the famous university think-tank [7].

Based on the above theory, the following assumption is put forward: 
$\mathrm{H}$ 2: The evaluation $\mathrm{f}$ job experience has a significant positive effect on the promotion possibility.

Zhou Jianguo believed that: in the enterprise, the salary system that can be promoted considers two factors: capacity and performance. Specifically in terms of the ability, it is measured by the staff's qualifications, work experience, to be rewarded, organizational performance, and then based on the importance of these four aspects on the ability affect, to design the different weights, then design these four different weights into the pay factor, to carry out the corresponding score calculation based on the lifting of employees' ability or not, and then according to the score of ability to make staff to be promoted [8].

Based on the above theory, the following assumption is put forward:

H3: As an intermediate variable in the evaluation of job experience and promotion possibility, the ability accumulation has a positive effect on the promotion possibility.

\section{A. Research Sample}

In order to ensure the reliability and validity of the questionnaire survey, on the basis of being clear about the research content and purpose, the management staff of central enterprises was selected as the research object. Questionnaires researched are from 773 employees of State-owned enterprises' 19 subsidiary units, of which $72 \%$ of survey participants who are from the three sub units of State-owned enterprises, $28 \%$ of survey participants who are from the two sub units of State-owned enterprises. Finally, the number of available questionnaires was 773.After the effectiveness of screening, a total of 742 valid questionnaires was entered into the final statistical analysis stage.

\section{B. Variables Measurement}

The measurement indicators of 3 latent variables are selected. They are the evaluation of job experience, ability accumulation and promotion possibility, as shown in Table I.

\section{RESEARCH DESIGN}

TABLE I. MEASUREMENT MODEL OF LATENT VARIABLES IN MANAGEMENT

\begin{tabular}{|c|c|c|}
\hline Latent variables & Measurement index & Measurement index nomenclature \\
\hline \multirow{4}{*}{$\begin{array}{c}\text { Promotion } \\
\text { possibility } \\
\eta 1\end{array}$} & $\mathrm{Y} 1$ & The length of job seniority \\
\hline & $\overline{\mathrm{Y} 2}$ & The number of job rotation \\
\hline & Y3 & Taking part in job training \\
\hline & Y4 & Job performance evaluation results \\
\hline \multirow{7}{*}{$\begin{array}{l}\text { The evaluation of } \\
\text { job experiencen } 2\end{array}$} & Y5 & Frontline job \\
\hline & Y6 & Junior section job \\
\hline & Y7 & Senior section job \\
\hline & Y8 & Deputy director positions \\
\hline & Y9 & Full time education training \\
\hline & $\mathrm{Y} 10$ & On the job training \\
\hline & Y11 & On the job diploma training \\
\hline \multirow{4}{*}{$\begin{array}{c}\text { Ability } \\
\text { accumulation } \xi\end{array}$} & $\mathrm{X} 1$ & Operatives' work experience ability accumulation \\
\hline & $\mathrm{X} 2$ & First-line manager's job experience ability accumulation \\
\hline & $\mathrm{X} 3$ & Middle manager's job experience ability accumulation \\
\hline & $\mathrm{X} 4$ & Top manager's position ability accumulation \\
\hline
\end{tabular}

\section{DATA ANALYSIS}

\section{A. Data Reliability and Validity Analysis}

The internal reliability and validity of the questionnaire were analyzed before the hypotheses were made. Usually using the alpha reliability coefficient method (Cronbach $\alpha$ ) to carry on the reliability analysis, the results as shown in Table II. 
TABLE II. RELIABILITY ANALYSIS

\begin{tabular}{|c|c|c|}
\hline Latent variables & Explicit variables & Cronbach $\alpha$ \\
\hline \multirow{4}{*}{ Promotion possibility } & The length of job seniority & \multirow{4}{*}{0.750} \\
\hline & The number of job rotation & \\
\hline & Taking part in job training & \\
\hline & Job performance evaluation results & \\
\hline \multirow{7}{*}{$\begin{array}{c}\text { The evaluation of job } \\
\text { experience }\end{array}$} & Frontline job & \multirow{7}{*}{0.815} \\
\hline & Junior section job & \\
\hline & Senior section job & \\
\hline & Deputy director positions & \\
\hline & Full time education training & \\
\hline & On the job training & \\
\hline & On the job diploma training & \\
\hline \multirow{4}{*}{ Ability accumulation } & Operatives' work experience ability accumulation & \multirow{4}{*}{0.782} \\
\hline & First-line manager's job experience ability accumulation & \\
\hline & Middle manager's job experience ability accumulation & \\
\hline & Top manager's position ability accumulation & \\
\hline
\end{tabular}

From Table II, we can see that the Cronbach $\alpha$ of the latent variables is above 0.75 , which shows that the internal reliability of the scale is higher. Validity analysis, usually use the KMO sample measurement and Bartlett Test of Sphericity (Bartlett Test of Sphericity) method, the measurement results as shown in Table III.

TABLE III. KMO AND BARTLETT TEST

\begin{tabular}{c|c|c}
\hline \multicolumn{2}{c|}{ Kaiser-Meyer-Olkin metri for sampling sufficient degree } & .845 \\
\hline \multirow{2}{*}{$\begin{array}{c}\text { Inspection of Bartlett's degree of } \\
\text { roundness }\end{array}$} & Approximate chi square & 962.848 \\
\cline { 2 - 3 } & df. & 120 \\
\cline { 2 - 3 } & Sig. & .000 \\
\hline
\end{tabular}

The results showed that: KMO value was 0.845 , its value is close to 1 , the more suitable for factor analysis; Bartlett hemispherical test of sig value was 0 , less than 0.01 , you can carry out factor analysis. It shows that the scale has good internal validity.

\section{B. Structural Equation Model Analysis}

In order to verify the research hypotheses, the structural equation model is constructed in AMOS 21. In this model, there are 3 latent variables and 15 observed variables. The specific situation is shown in figure 1 .

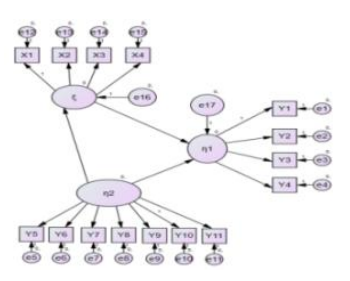

Figure.1. Initial model of structural equation

TABLE IV. MODEL FIT INDEX

\begin{tabular}{c|c|c|c|c|c}
\hline Chi square value & The value of P & RMSEA & NFI & TLI & CFI \\
\hline 192.365 & 0.000 & 0.066 & 0.793 & 0.821 & 0.870 \\
\hline
\end{tabular}

In the initial model fit index, the chi square value is 192.365 , the value of the chi square should be as small as possible. The probability $P$ value is 0 , less than 0.05 , which reaches the significant level. The RMSEA value is 0.066 , and the RMSEA value is lower than 0.05 , which indicates that the model is fit to the data.NFI is 0.793 , TLI is 0.821 , CFI is 0.870 ,also less than 0.90 ; so the model needs to be modified. According to the modified index MI in AMOS, so remove the Y2, Y3, Y8, Y9 variables to modify. New model fitness metrics are shown in Table $\mathrm{V}$. 
TABLE V. MODEL FIT INDEX

\begin{tabular}{c|c|c|c|c|c}
\hline Chi square value & The value of P & RMSEA & NFI & TLI & CFI \\
\hline 101.097 & 0.000 & 0.05 & 0.876 & 0.871 & 0.920 \\
\hline
\end{tabular}

Among them, the chi square value is 101.097, compared to the previous, the value of the chi squareis reduce. The $\mathrm{P}$ value was 0 , less than 0.05 , and the significant level was reached. RMSEA is 0.05 , which shows that the model and data fitting degree is good.NFI is 0.876 , TLI is 0.871 , CFI is 0.92 , and the 3 parameter values are close to 1 . It is considered that the modified model is better fit for the data. The correction model is shown in figure 2.

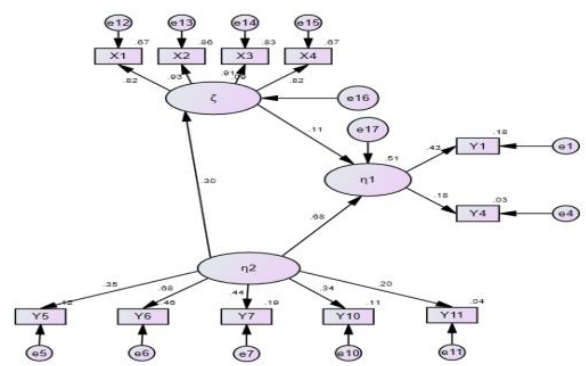

Figure.2. Modified model

The standardized path coefficients of the modified model are shown in Table VI.

TABLE VI. PATH COEFFICIENT ESTIMATION

\begin{tabular}{c|c|c|c|c}
\hline & Standardized path coefficient & S.E & C.R. & P \\
\hline $\mathrm{H}_{1}: \zeta \leftarrow \eta 2$ & 0.30 & 0.703 & 1.674 & 0.094 \\
\hline $\mathrm{H}_{2}: \eta 1 \leftarrow \eta 2$ & 0.68 & 0.883 & 1.755 & 0.079 \\
\hline $\mathrm{H}_{3}: \eta 1 \leftarrow \zeta \leftarrow \eta 2$ & 0.41 & 0.742 & 0.607 & 0.044 \\
\hline
\end{tabular}

\section{V.CONCLUSIONS}

A. Paying Attention to the Job Experience of Staff, Providing the Standard Guide for the Ability Accumulation of Employees

The evaluation of job experience has a significant positive effect on the ability accumulation. Therefore, enterprises should pay more attention to the employees' job experience, employees should also pay attention to their own job experience, and especially for grass-roots position's working experience.

\section{B. Quantifying Employees' Job Experience, to Provide Standards for Employees' Promotion Possibility}

The evaluation of job experience has a significant positive impact on the promotion possibility. Enterprises quantify the employee's job experience, such as the number of job seniority, job rotation number, to measure the employee promotion possibility. Therefore, based on the research, this paper proposes the best job seniority, job rotation number standards for enterprises to provide an objective basis for selecting personnel. In the frontline job, the best job seniority is 1-2 years, only to be promoted to a high level post; in the junior section job and senior section job, the best job seniority is 3-4 years, can be promoted to a high level post. In the frontline positions, junior section job, senior section job, deputy director positions, the best job rotation numbers are 2 times, only to be promoted to a high level post.

\section{Paying Attention to the Capacity Accumulation of Staff, Enhancing Their Own Promotion Possibility}

As an intermediate variable between the evaluation of job experience and promotion possibility, the ability accumulation has a significant positive effect on the promotion possibility. Therefore, enterprises should pay attention to the employees' ability accumulation, and constantly improve the employees' ability, so the employee's promotion possibility could be raised and employees could obtain the greater promotion chance.

\section{Promotion Possibility Achieving the Main Body Consciousness of Employee, Fostering Own Ability to Match Promotion Position}

The existing promotion mechanism is divided into two categories: one is the selection, the other one is the appointment. But in the actual practice, promotions are mostly based on appointment, a passive way of promotion which failed to play the role of incentive. By studying the relationship among the promotion possibility, ability accumulation and job experience, promotion possibility realizes the main body consciousness of employee, so that they can enhance the awareness of the cultivation of self-promotion ability, making promotion a real incentive. 


\section{REFERENCES}

[1] Yang Ruilong, Wang Yuan, Nie Huihua. The promotion mechanism of "quasi-official": evidence from Chinese central enterprises,J.Manage the world journal,2013,03:23-33.

[2] Teece D, Pisano G, Shuen A.Dynamic capabilities and strategic management, J.Strategic Management Journal,1997,(18): 509-533.

[3] Richardson,G.B."The Organization ofIndustry”, J. The Economic Journal, 1972, Vol.82, 883-896.

[4] Dragoni,Lisa.Developing executive leaders:The relative contribution of cognitive ability,personality,and the accumulation of work experience in predicting strategic thinking competency, J. Personnel Psychology.Winter,2011,vol.64,p829-864.
[5] Huang Simei, Lian Zhaolong. To investigate the relationship between promotion possibility index,jealousy performance and rank difference, J.The journal of the knowledge economy,2015,20:16-18.

[6] Yin Weiguo. The philosophical thinking on the experience of the cadre's post office experience, J.Journal of Nanjing political college journals, 2001, 03:90-92.

[7] Zhang Xinpei, Zhao Wenhua, who works for a famous university think tank: a structured network analysis based on the experience of the staff, J.Tsinghua university journal of education research,2014 06:59-65.

[8] Zhou Jianguo. Design of the compensation system based on competence and performance: a case study of AJ Company,J. China Human Resource Development,2009,11:42-44. 